\title{
IMPLEMENTASI PENDIDIKAN SIAGA BENCANA DI SDN PURWOSEKAR
}

\author{
Yuli Yana ${ }^{1}$, Danang Abdurrahman ${ }^{2}$
}

\author{
Keywords : \\ Bencana, \\ SDN Purwosekar, \\ Sagana.

\section{Corespondensi Author} \\ ${ }^{1}$ Pendidikan Geografi, Universitas \\ Negeri Malang \\ Kabupaten Kediri \\ Email: yuliyanapgeo@gmail.com
}

\begin{abstract}
Abstrak. Indonesia merupakan negara yang memiliki banyak potensi bencana. Banyaknya potensi bencana tersebut seharusnya diimbangi oleh sumber daya manusia yang siap siaga dalam menghadapi bencana. Oleh sebab itu dalam kegiatan pengabdian masyarakat Mahasiswa KKN Universitas Negeri Malang 2019 menyelenggarakan kegiatan dibidang kebencanaan. Kegiatan tesebut yakni Implementasi Sekolah Siaga Bencana yang bertujuan untuk memberikan edukasi early warning system ketika terjadi bencana gempa bumi. Kegiatan tersebut dilakukan hari senin dan selasa, tanggal 24 dan 25 Juni 2019 bertempat di SD Negeri 1 dan 2 Purwosekar. Sasaran kegiatan tersebut adalah peserta didik sekolah dasar kelas 4-6. Susunan kegiatan yang dilakukan ialah pemberian materi yang dikemas dalam bentuk story telling, bernyanyi, game, dan simulasi. Penyampaian materi dikemas semenarik mungkin sehingga dapat diterima oleh peserta didik dengan mudah. Hasil yang diperoleh dari kegiatan tersebut ialah pengetahuan serta pengalaman peserta didik mengenai ilmu kebencanaan khsususnya kesiapsiagaan menghadapi bencana gempa bumi.
\end{abstract}

(i) This work is licensed under a Creative Commons Attribution 4.0 International License

\section{Pendahuluan}

Bencana alam merupakan fenomena alam yang mengancam keberlangsungan hidup manusia. Menurut undang-undang No 24 Tahun 2007 bencana ialah rangkaian peristiwa yang mengancam dan menganggu kehidupan dan penghidupan masyarakat yang disebabkan oleh faktor alam maupun non alam. Bencana alam meliputi gempa bumi, tsunami, gunung meletus, angin topan, dan lain sebagainya. Sedangkan bencanan non alam meliputi gagalnya teknologi, gagal modernisasi, epidemi, wabah penyakit, dan lain sebagainya. Bencana alam merupakan peristiwa yang memberikan dampak negatif dalam bidang materi dan non materi. Bencana yang disebabkan oleh faktor alam sering kali terjadi dalam waktu yang tidak terduga-duga dan dapat terjadi dimana saja pada siapa saja.

Bencana alam merupakan salah satu ciri dari Negara Indonesia, negara Indonesia sempat dijuluki sebagai supermarket bencana oleh BMKG. Julukan tersebut memiliki arti bahwa di Indonesia memiliki bencana yang bermacammacam. Banyaknya potensi bencana alam yang dapat terjadi di Indonesia seharusnya diimbangi dengan sumber daya manusia yang memiliki kapasitas memadai dalam hal kesiapsiagaan terhadap bencana. Namun sayangnya pengetahuan akan kesiapsiagaan menghadapi bancana belum dimiliki oleh sebagian besar masyarakat di Indonesia. Hal tersebut menjadikan dampak bencana yang terjadi semakin tinggi. 
Rangkaian peristiwa bencana yang terjadi memberikan banyak pengalaman empiris tentang kejadian yang membawa korban. Masyarakat pada umumnya memiliki pengetahuan dalam memprediksi dan melakukan mitigasi bencana alam. Berdasarkan hal tersebut, disadari bahwa pemahaman tentang bencana alam harus dimiliki oleh semua orang. Diperlukan upaya konkret dalam memahami dan mengantisipasi kondisi secara terpadu. Salah satu wujudnya, melalui upaya pengurangan risiko bencana yang berbasis pendidikan. Pendidikan menjadi salah satu sarana yang efektif untuk mengurangi risiko bencana dengan memberikan pemahaman kepada pendidik maupun peserta didik. Presiden Jokowi dalam sidang kabinet paripurna hari Senin taggal 7 Januari 2019 mengusulkan bahwa edukasi mitigasi bencana sudah saatnya dimasukan dalam kurikulum pendidikan di Indonesia mengingat Indonesia banyak terjadi bencana.

Usulan terkait perlunya edukasi kesiapsiagaan bencana tersebut menjadi salah satu alasan perancangan program kerja implementasi sekolah siaga bencana. Lokasi pelaksanaan program kerja tersebut berada di Desa Purwosekar Kecamatan Tajinan Kabupaten Malang berupa sekolah dasar negeri 1 dan 2. Pendidikan kesiagsiagaan dalam menghadapi bencana merupakan wujud respon yang dilakukan seseorang terhadap suatu bencana. Pihak yang berperan dalam hal ini adalah masyarakat dan pihak yang berwenang dalam hal kebencanaan. Sikap kesiapsiagaan masyarakat yang perlu di miliki adalah adanya pengetahuan, sikap, dan perilaku mengenai bencana. Sikap siaga bencana yang dimiliki masyarakat merupakan wujud dari pembangunan yang berkelanjutan. Jika hal tersebut tercapai maka pembangunan akan lebih baik, mempersiapkan masyarakat dalam menghadapi bencana untuk meminimalisir dampak.

Bencana dan risikonya merupakan suatu hal yang tidak dapat terpisahkan dari kehidupan manusia. Namun risiko bencana dapat diminimalisir dengan manajemen risiko bencana yaitu mempelajari bencana pada pra, saat, dan pasca bencana. Kegiatan pra banyak dilupakan, padahal justru pada tahap tersebut bencana sangatlah penting dipelajari karena merupakan modal dalam menghadapi bencana. Kegiatan saat bencana juga penting yaitu berupa kegiatan tanggap darurat untuk meringankan penderita. Sedangkan pada kegiatan pasca mencakup pemulihan, rehabilitasi, dan rekontruksi.
Berdasarkan pengamatan, selama ini banyak kegiatan yang dilakukan adalah pasca bencana. Padahal apibila kita memiliki sedikit perhatian terhadap kegiatan-kegiatan sebelum bencana, maka kita dapat mereduksi potensi bahaya atau kerugian yang mungkin timbul ketika bencana.

\section{Metode}

\section{Pendekatan}

Pendekatan yang digunakan dalam kegiatan Sekolah Siaga Bencana (SAGANA) yaitu deskriptif kualitatif. Pendekatan yang demikian bertujuan untuk menggambarkan sifat sesuatu yang tengah berlangsung pada saat studi. Pendekatan tersebut memberikan informasi yang lengkap terkait program kerja yang dilakukan Mahasiswa UM tahun 2019 berupa implementasi sekolah siaga bencana.

\section{Tahapan}

Tahapan dari kegiatan implementasi pendidikan siaga bencana yaitu:

1. Sebelum

Ijin kegiatan dan menyesuaikan tanggal pelaksanaan kegiatan KKN UM 2019 dengan kegiatan di sekolah.

2. Saat

Melaksanakan kegiatan implementasi sekolah siaga bencana dengan susunan kegiatan yaitu story telling mengenai kebencanaan, bernyanyi lagu siap siaga bencana, game menentukan jalur evakuasi sesuai dengan denah sekolah yang sudah disiapkan, dan terakhir adalah simulasi terjadinya bencana gempa bumi. Simulasi dilakukan dengan bermain peran. Adapun peran yang dilakukan peserta didik yaitu PMR, Informan, huntara, dan korban.

3. Sesudah

Mahasiswa KKN UM memberikan sertifikat dan infografis yang berisikan langkah penting mitigasi bencana gempa bumi.

Berikut tahapan kegiatan implementasi pendidikan siaga bencana: 


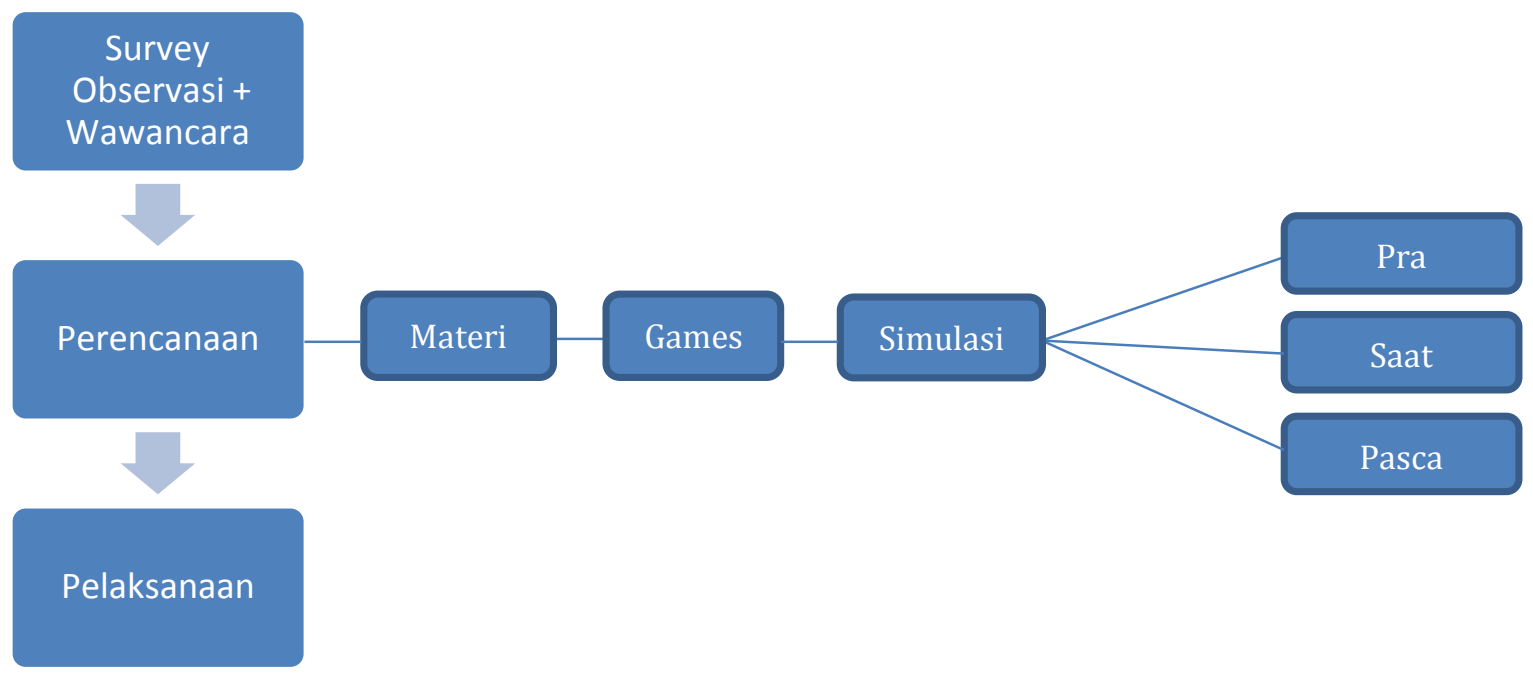

Bagan 1. Tahapan implementasi pendidikan siaga bencana.

\section{Lokasi}

Lokasi pelaksanaan kegiatan implementasi sekolah siaga bencana di SD Negeri Purwosekar.

\section{Durasi Waktu}

Durasi kegiatan implementasi sekolah siaga bencana berlangsung mulai dari jam 08.00 -11.00 WIB. Dilakukan 2 hari di 2 sekolah dasar di Desa Purwosekar.

\section{Hasil dan Pembahasan}

Adapun keguatan yang dilakukan dalam implementasi pendidikan siaga bencana yaitu sebagai berikut:

\section{Story Telling}

Konsepan yang kami berikan untuk menjalankan pendidikan siaga bencana di SDN Purwosekar dengan bermodelkan story telling. Pada mulanya ada penampilan video berupa lagu yang inti sarinya berupa penyampaian bahwa di Negara kita Indinesia merupakan Negara yang memiliki beragam bencana. Video tersebut untuk menarik perhatian anak-anak agar terfokus pada kami. Selanjutnya kami memberika sebuah cerita yang diperankan oleh saudari trisna, yusrir, dan uhkti. Mereka bermain peran sesuai dengan cerita yang dibawakan. Bermain peran tersebut memanfaatkan wayang sebagai tokohnya.

Penyampaian story telling sangat hening dan anak-anak memperhatikan dengan baik. Story telling tersebut berisikan sebuah percakaan antara bumi, matahari, dan tiwi. Matahari yang sangat kagum dengan bumi karena memiliki segalanya bagi manusia. Namun dilain sisi bumi juga menjadi sumber bencana bagi manusia.
Tokoh tiwi dalam cerita tersebut ia adalah seorang anak yang memiliki kemampuan dan pengetahuan terhadap kebencanaan. Oleh sebab itu story telling atau cerita tersebut isinya mengajak anak-anak agar mau belajar bersama mengenai kebencanaan.

\section{Materi}

Materi merupakan kegiatan yang dilakukan setelah story telling yatu berupa video. Materi yang disampaikan adalah video kebencanaan dan upaya mitigasinya yang sudah kami siapakan dari Badan Nasioanal Penanggulangan Bencana (BNPB). Mereka membimbing anak-anak untuk agar mudah memahami isi dari video. Selain video, kami juga mempersiapkan lagu kebencanaan yang dinyanyikan bersama-sama setelah penayangan materi dalam video sudah berakhir. Akhir kegiatan terdapat kuis yang berhadiah. Kuis tersebut berupa penentuan lokasi rawan dan aman terhadap bencana. Bagi anak-anak yang bisa menjawab maka akan mendapat hadiah berupa seperangkat alat belajar.

\section{Simulasi}

Kegiatan terakhir dari acara pendidikan siaga bencana adalah simulasi atau bermain peran ketika ada bencana. Bencana yang kami ambil adalah gempa bumi. Simulasi kali ini kami membagi beberapa peranan yang harus dilakukan oleh anak-anak. Kemi menunjuk anak kelas 6 yang berjumlah 6 orang untuk menjalankan peran yang sudah ditentukan. Peran tersebut diantaranya:

\section{PMR Alat}


Yuli Yana, Danang Abdurrahman. Implementasi Pendidikan Siaga Bencana SDN Purwosekar

2. Informan

3. Huntara

4. Korban

Hasil pelaksanaan kegiatan implementasi sekolah siaga bencana yaitu:

1. Peserta didik memperoleh pengetahuan dan wawasan tentang potensi bencana yang ada di Indonesia. Selain itu bencana di Indonesia peserta didik juga mengetahui potensi bencana yang ada di lingkunganya.

2. Peserta didik dapat memiliki ketrampilan kesiapsiagaan dalam mengahadapi bencana gempa bumi.

Berikut adalah dokumentasi kegiatan implementasi pendidikan siaga bencana:

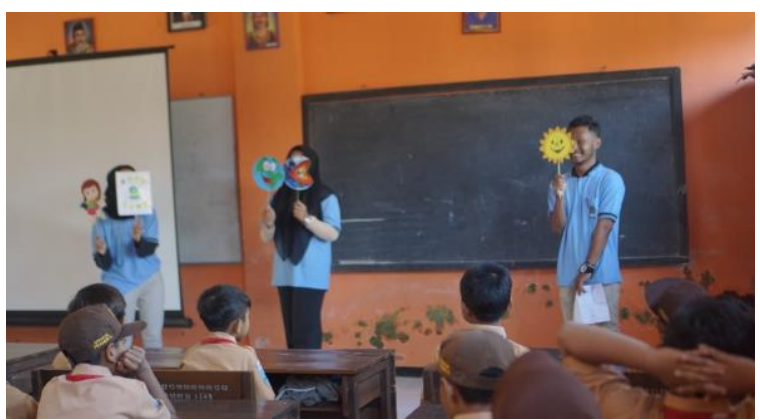

Gambar 1: Tim Memberikan Story Telling dengan tema kebencanaan

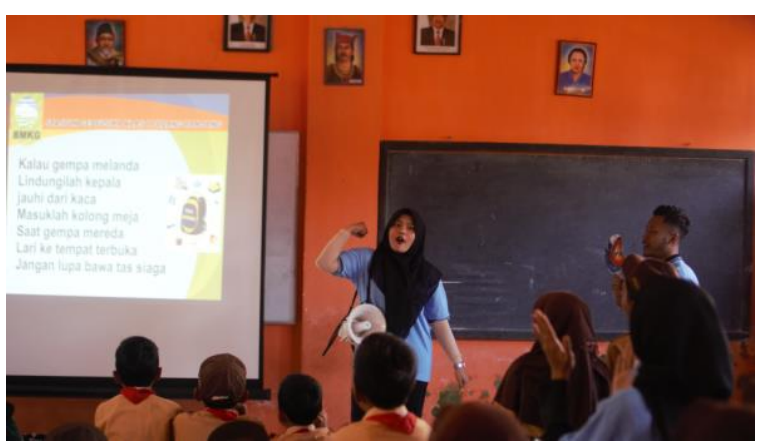

Gambar 2: Tim Memberikan Materi dengan tema kebencanaan

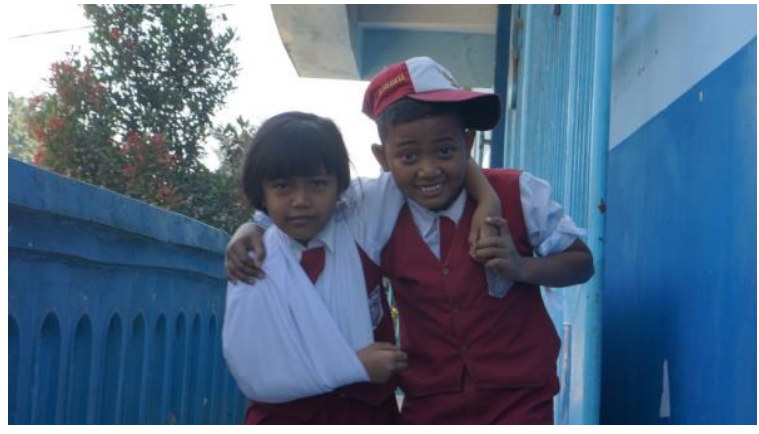

Gambar 3: Kegiatan Simulasi Bencana

Gempa

\section{Simpulan dan Saran}

\section{Simpulan}

Kegiatan Implementasi Sekolah Siaga Bencana bertujuan untuk memberikan edukasi early warning system ketika terjadi bencana gempa bumi. Kegiatan tersebut dilakukan hari senin dan selasa, tanggal 24 dan 25 Juni 2019 betempatan di SD Negeri Purwosekar. Susunan kegiatan yang dilakukan ialah pemberian materi yang dikemas dalam bentuk story telling, bernyanyi, game, dan simulasi. Kegiatan berjalan dengan lancar dan mendapat sambutan baik dari peserta didik sendiri dan dari guru sekolah dasar tersebut.

\section{Saran}

Kegiatan Implementasi Sekolah Siaga Bencana merupakan kegiatan yang perlu dilakukan di seluruh sekolah di Indonesia. Mengingat Indonesia merupakan negara dengan potensi bencana yang sangat banyak. Maka Pendidikan siaga bencana penting dilakukan.

\section{Daftar Rujukan}

Anonim. 2007. Undang-Undang Nomor 24 Tahun 2007 tentang Penanggulangan Bencana.

Lembaran Negara Republik Indonesia tahun 2007 nomor 66 : Bencana. Paper Gladien Fundamental dalam Upaya Mitigasi dan Penanganan Tanggap Darurat Jakarta. 
Yuli Yana, Danang Abdurrahman. Implementasi Pendidikan Siaga Bencana SDN Purwosekar

Kodoatie, J.Robert dan Sugiyanto. 2002. Banjir Beberapa Penyebab: Pustaka Pelajar.

LIPI - UNESCO/ISDR. 2006. Kajian Kesiapsiagaan Masyarakat Dalam Mengantisipasi Bencana Gempa Bumi dan Tsunami. Jakarta. Metode Pengendaliannya dalam Perspektif Lingkungan. Yogyakarta

Sadisun, A. Imam. 2008. Pemahaman Karakteristik Bencana : Aspek: Pustaka Pelajar.

Desfandi, M. 2014. Urgensi Kurikulum Pendidikan Kebencanan Berbasis Kearifan Lokal Di Indonesia. https://www.researchgate.net/publicati on/295101285.

BNPB, 2018. Buku Saku, Tanggap Tangkas Tangguh Menghadapi Bencana. Pusat Data Informasi dan Humas BNPB.

BNPB, 2017. Buku Pedoman Latihan Kesiapsiagaan Bencana, Membangun Kesadaran, Kewaspadaan dan Kesiapsiagaan dalam Menghadapi Bencana, direktorat kesiapsiagaan, deputi bidang pencegahan dan kesiapsiagaan BPNP.Undang-Undang Republik Indonesia Nomor 24 Tahun 2007 Tentang Penaggulangan Bencana.

UNDP (1992). Tinjauan Umum Manajemen Bencana. Program Pelatihan Manajemen Bencana : Edisi kedua.(http://www.undp.go.id)

UNDP (1994). Mitigasi Bencana. Program Pelatihan Manajemen Bencana: Edisi kedua.(http://www.undp.go.id)

Yayasan IDEP (2007), Penanggulangan Bencana Berbasis Masyarakat. Yayasan IDEP -Ubud, UNESCO Jakarta. 